\title{
Association of candidate gene polymorphisms with bone mineral density in community-dwelling Japanese women and men
}

\author{
YOSHIJI YAMADA ${ }^{1}$, FUJIKO ANDO ${ }^{2}$ and HIROSHI SHIMOKATA ${ }^{2}$ \\ ${ }^{1}$ Department of Human Functional Genomics, Life Science Research Center, Mie University, Tsu, Mie; \\ ${ }^{2}$ Department of Epidemiology, National Institute for Longevity Sciences, Obu, Aichi, Japan
}

Received December 27, 2006; Accepted February 6, 2007

\begin{abstract}
Although bone mineral density (BMD) is a complex trait that is influenced by both genetic and environmental factors, heritability studies in twins and families have shown that genetic factors account for $60-85 \%$ of the variance in BMD. We examined the relations of six candidate gene polymorphisms to BMD in community-dwelling women and men. The 2238 subjects (1110 women, 1128 men) were aged 40-79 years and were randomly recruited to a population-based prospective cohort study of aging and age-related diseases in Japan. BMD at the distal and proximal radius was measured by peripheral quantitative computed tomography, and BMD for the total body, lumbar spine (L2-L4), right femoral neck, and right trochanter was measured by dual-energy $\mathrm{X}$-ray absorptiometry. Genotypes for the 1019C $\rightarrow \mathrm{T}$ (Pro319Ser) polymorphism of GJA4 and the $1462 \mathrm{~A} \rightarrow \mathrm{G}$ (Lys469Glu) polymorphism of ICAMI were determined with a fluorescencebased allele-specific DNA primer assay system, and those for the $386 \mathrm{G} \rightarrow \mathrm{A}$ (Ala99Thr) polymorphism of $P L O D 1$, the $\mathrm{A} \rightarrow \mathrm{G}$ polymorphism of $C N R 2$, the $1583 \mathrm{G} \rightarrow \mathrm{A}$ (Arg528Lys) polymorphism of $A L A P$, and the $-514 \mathrm{C} \rightarrow \mathrm{T}$ polymorphism of $L I P C$ were determined by melting curve analysis. The polymorphisms of ALAP and PLODI were associated with BMD in premenopausal women; those of ICAMI and $L I P C$ with BMD in postmenopausal women; that of $C N R 2$ with BMD in premenopausal and postmenopausal women; and that of GJA4 with BMD in men. Among these polymorphisms, those of $I C A M 1, C N R 2$, and GJA4 were markedly associated with BMD. These results suggest that ALAP, PLODI, ICAMI, $L I P C$, and $C N R 2$ are susceptibility loci for reduced bone mass in Japanese women and that GJA4 constitutes such a locus in Japanese men. The polymorphisms of ICAMI and $C N R 2$ may confer susceptibility to postmenopausal osteoporosis in women, and that of GJA4 to osteoporosis in men.
\end{abstract}

Correspondence to: Dr Yoshiji Yamada, Department of Human Functional Genomics, Life Science Research Center, Mie University, 1577 Kurima-machiya, Tsu, Mie 514-8507, Japan

E-mail: yamada@gene.mie-u.ac.jp

Key words: polymorphism, genetics, osteoporosis, bone density, CNR2, PLOD1, GJA4, ALAP, LIPC, ICAM1

\section{Introduction}

Osteoporosis, a major health problem of the elderly, is characterized by a reduction in bone mineral density (BMD) and a deterioration in the microarchitecture of bone, both of which result in predisposition to fractures (1). Although reproductive, nutritional, and lifestyle factors influence BMD, family and twin studies have suggested that BMD is largely $(60-85 \%)$ heritable and under the control of multiple genes (2-4). Personalized prevention of osteoporosis and osteoporotic fractures is an important public health goal, for which one approach is to identify disease susceptibility genes. Although genetic linkage analyses (5-7) and candidate gene association studies (7-10) have implicated various loci and genes in predisposition to osteoporosis or fractures, the genes that confer susceptibility to this disease remain to be identified definitively. In addition, because of ethnic differences in gene polymorphisms as well as in lifestyle and other environmental factors, it is important to examine polymorphisms related to BMD in each ethnic group.

We have been attempting to identify genes significantly associated with BMD in Japanese women or men with a population-based approach. In the present study, we selected six candidate genes that might be expected to contribute to bone remodeling (Table I) and examined the relations of polymorphisms of these genes to BMD, even though there is no apparent biological link among these genes. Our aim was to identify a single polymorphism significantly associated with BMD for each gene. Among several polymorphisms previously identified, we selected those that might be expected to affect gene function. We thus examined the relations of these polymorphisms to BMD in community-dwelling Japanese women and men.

\section{Materials and methods}

Study population. The National Institute for Longevity Sciences - Longitudinal Study of Aging is a population-based prospective cohort study of aging and age-related diseases, the details of which have been described previously (11-15). Individuals with disorders known to cause abnormalities of bone metabolism, including diabetes mellitus, chronic renal failure, rheumatoid arthritis, as well as thyroid, parathyroid, adrenal, and other endocrine diseases, or those who had taken drugs that affect bone metabolism, such as estrogen, 
Table I. The six gene polymorphisms examined in the present study.

\begin{tabular}{llccc}
\hline Locus & \multicolumn{1}{c}{ Gene } & Symbol & Polymorphism & dbSNP \\
\hline 1p36.3-36.2 & Procollagen-lysine, 2-oxoglutarate 5-dioxygenase & PLOD1 & 386G $\rightarrow$ A (Ala99Thr) & rs7551175 \\
$1 \mathrm{p} 36.11$ & Cannabinoid receptor 2 & CNR2 & A $\rightarrow$ G & rs2501431 \\
1 p35.1 & Gap junction protein, $\alpha-4$ & GJA4 & 1019C $\rightarrow$ T (Pro319Ser) & rs1764391 \\
$5 q 15$ & Adipocyte-derived leucine aminopeptidase & ALAP & 1583G $\rightarrow$ A (Arg528Lys) & rs30187 \\
$15 q 21-23$ & Lipase, hepatic & LIPC & -514C $\rightarrow$ T & rs1800588 \\
19 p13.3-13.2 & Intercellular adhesion molecule 1 & ICAM1 & 1462A $\rightarrow$ G (Lys469Glu) & rs5498 \\
\hline
\end{tabular}

glucocorticoids, bisphosphonates, and vitamin D, were excluded from the present study. We thus examined the relations of gene polymorphisms to BMD in 2238 individuals (1110 women and 1128 men). Individuals whose genotypes were not successfully determined were also excluded from the analysis. In addition, to uncover potential differences between women according to menopausal status, we conducted all analyses for premenopausal and postmenopausal women separately. Menopausal status was evaluated with a detailed questionnaire, and menopause was defined as complete cessation of menstruation. Because of their small number $(n=19)$, perimenopausal women were excluded from this analysis. The study protocol complied with the Declaration of Helsinki and was approved by the Committee on Ethics of Human Research of the National Institute for Longevity Sciences. Written informed consent was obtained from each subject.

Measurement of BMD. BMD at the radius was measured by peripheral quantitative computed tomography (pQCT) with a Desiscan 1000 instrument (Scanco Medical, Bassersdorf, Switzerland) and was expressed as D50 (BMD for the inner $50 \%$ of the cross-sectional area of the distal radius, comprising mostly cancellous bone), D100 (BMD for the entire crosssectional area of the distal radius, including both cancellous and cortical bone), and P100 (BMD for the entire crosssectional area of the proximal radius, consisting mostly of cortical bone). BMD for the total body, lumbar spine (L2-L4), right femoral neck, and right trochanter was measured by dual-energy X-ray absorptiometry (DXA) with a QDR 4500 instrument (Hologic, Bedford, MA, USA). The coefficients of variation of the pQCT instrument for BMD values were $0.7 \%$ (D50), $1.0 \%$ (D100), and $0.6 \%$ (P100), and those of the DXA instrument were $0.9 \%$ (total body), $0.9 \%$ (L2-L4), $1.3 \%$ (femoral neck), and $1.0 \%$ (trochanter).

Determination of genotype. Genotypes for polymorphisms of GJA4 and ICAMI were determined with a fluorescencebased allele-specific DNA primer assay system (Toyobo Gene Analysis, Tsuruga, Japan) (16). Primers and other conditions for genotyping are shown in Table II. The polymorphic region of each gene was amplified by the polymerase chain reaction (PCR) with allele-specific sense primers labeled at the $5^{\prime}$ end with either fluorescein isothiocyanate (FITC) or Texas red and with an antisense primer labeled at the 5' end with biotin. The reaction mixture $(25 \mu \mathrm{l})$ contained $20 \mathrm{ng}$ of DNA, 5 pmol of each primer, $0.2 \mathrm{mmol} / \mathrm{l}$ of each deoxy- nucleoside triphosphate, 2.5 or $4.5 \mathrm{mmol} / 1 \mathrm{MgCl}_{2}$, and $1 \mathrm{U}$ of rTaq DNA polymerase (Toyobo, Osaka, Japan) in polymerase buffer. The amplification protocol comprised an initial denaturation at $95^{\circ} \mathrm{C}$ for $5 \mathrm{~min} ; 35$ cycles of denaturation at $95^{\circ} \mathrm{C}$ for $30 \mathrm{sec}$, annealing at $60^{\circ} \mathrm{C}$ for $30 \mathrm{sec}$, and extension at $72^{\circ} \mathrm{C}$ for $30 \mathrm{sec}$; and a final extension at $72^{\circ} \mathrm{C}$ for $2 \mathrm{~min}$. The amplified DNA was incubated with streptavidinconjugated magnetic beads in the wells of a 96-well plate at room temperature, and the plate was then placed on a magnetic stand. The supernatants from each well were transferred to the wells of a 96 -well plate containing $0.01 \mathrm{~mol} / 1 \mathrm{NaOH}$ and were measured for fluorescence with a microplate reader (Fluoroscan Ascent; Dainippon Pharmaceutical, Osaka, Japan) at excitation and emission wavelengths of 485 and $538 \mathrm{~nm}$, respectively, for FITC; and of 584 and $612 \mathrm{~nm}$, respectively, for Texas red.

Genotypes for polymorphisms of PLOD1, CNR2, ALAP, and $L I P C$ were determined by melting curve analysis (intercalater-mediated fluorescence resonance energy transfer probe method). The polymorphic region of each gene was amplified by PCR (Table II) in a reaction mixture $(25 \mu \mathrm{l})$ containing $20 \mathrm{ng}$ of DNA, $5 \mathrm{pmol}$ of each primer, $0.2 \mathrm{mmol} / 1$ of each deoxynucleoside triphosphate, 2 or $3 \mathrm{mmol} / 1 \mathrm{MgCl}_{2}$, and $1.25 \mathrm{U}$ of rTaq DNA polymerase in polymerase buffer. The amplification protocol comprised an initial denaturation at $95^{\circ} \mathrm{C}$ for $5 \mathrm{~min} ; 45$ or 50 cycles of denaturation at $95^{\circ} \mathrm{C}$ for $30 \mathrm{sec}$, annealing at $65^{\circ} \mathrm{C}$ for $30 \mathrm{sec}$, and extension at $72^{\circ} \mathrm{C}$ for $30 \mathrm{sec}$; and a final extension at $72^{\circ} \mathrm{C}$ for $2 \mathrm{~min}$. A mixture (2 $\mu \mathrm{l}$ ) of $10 \mathrm{pmol}$ of probe and SYBR-Green was added to the PCR products, which were then transferred to a PRISM 7700 instrument (Applied Biosystems, Foster City, CA, USA) for measurement of melting temperature. The program for analytic melting comprised incubation at $95^{\circ} \mathrm{C}$ for $30 \mathrm{sec}$, $40^{\circ} \mathrm{C}$ for $1 \mathrm{~min}$, and temperatures increasing to $80^{\circ} \mathrm{C}$ over $10 \mathrm{~min}$. The fluorescence signals were detected at excitation and emission wavelengths of 485 and $612 \mathrm{~nm}$, respectively.

Statistical analysis. Data are presented as means \pm SE. Statistical analysis was performed with SAS software (SAS Institute, Cary, NC, USA). Data were compared among three genotype groups by one-way analysis of variance and the Tukey-Kramer post hoc test, and between two groups (dominant or recessive model) by the unpaired Student's t-test. BMD values were compared among genotypes for each polymorphism with adjustment for age, height, and body weight by the least squares method in a general linear model. Allele frequencies were estimated by the gene-counting 
Table II. Primers, probes, and other PCR conditions for genotyping.

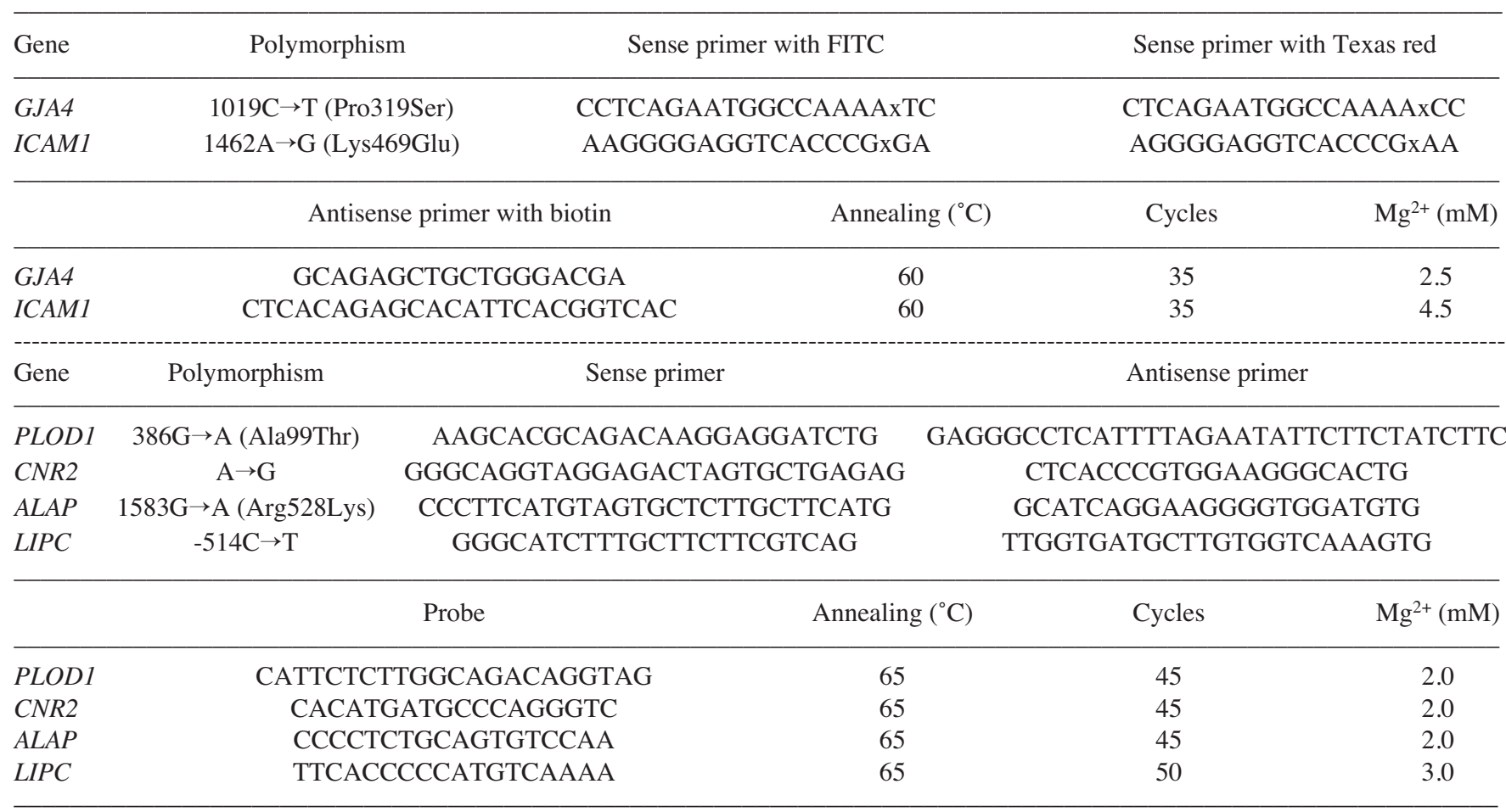

All primer and probe sequences are $5^{\prime} \rightarrow 3^{\prime}$.

method, and the Chi-square test was used to identify significant departure from Hardy-Weinberg equilibrium. A $\mathrm{P}$ value of $<0.05$ was considered statistically significant.

\section{Results}

Relation of the $386 G \rightarrow A$ (Ala99Thr) polymorphism of PLODI to $B M D$. The distribution of $386 \mathrm{G} \rightarrow \mathrm{A}$ genotypes of PLODI was in Hardy-Weinberg equilibrium, and age, height, and body weight did not differ among genotypes, for all women (Table III) or for premenopausal or postmenopausal women. Among all women, BMD for the femoral neck, with adjustment for age, height, and body weight, was greater in individuals with the $G G$ genotype than in those with the $G A$ genotype or in the combined group of $G A$ and $A A$ genotypes (Table III). BMD for the trochanter was also greater in individuals with the $G G$ genotype than in the combined group of $G A$ and $A A$ genotypes. The differences in BMD for

Table III. BMD and other characteristics for all women $(\mathrm{n}=1109)$ according to the PLOD1 genotype.

\begin{tabular}{|c|c|c|c|c|c|}
\hline Characteristic & $G G$ & $G A$ & $A A$ & $G G+G A$ & $G A+A A$ \\
\hline Number (\%) & $621(56.0)$ & $427(38.5)$ & $61(5.5)$ & $1048(94.5)$ & $488(44.0)$ \\
\hline Age (years) & $59.3 \pm 0.4$ & $59.0 \pm 0.5$ & $60.8 \pm 1.4$ & $59.2 \pm 0.3$ & $59.3 \pm 0.5$ \\
\hline Height $(\mathrm{cm})$ & $151.2 \pm 0.2$ & $151.4 \pm 0.3$ & $151.3 \pm 0.8$ & $151.3 \pm 0.2$ & $151.4 \pm 0.3$ \\
\hline Body weight $(\mathrm{kg})$ & $52.7 \pm 0.3$ & $52.4 \pm 0.4$ & $53.2 \pm 1.0$ & $52.6 \pm 0.3$ & $52.5 \pm 0.4$ \\
\hline \multicolumn{6}{|c|}{ BMD measured with pQCT $\left(\mathrm{mg} / \mathrm{cm}^{3}\right)$} \\
\hline D50 & $186.3 \pm 2.5$ & $183.5 \pm 3.0$ & $184.4 \pm 7.9$ & $185.2 \pm 1.9$ & $183.6 \pm 2.8$ \\
\hline D100 & $485.2 \pm 3.6$ & $486.8 \pm 4.3$ & $484.8 \pm 11.4$ & $485.9 \pm 2.8$ & $486.5 \pm 4.1$ \\
\hline P100 & $1158.0 \pm 5.8$ & $1146.3 \pm 7.0$ & $1164.1 \pm 18.3$ & $1153.3 \pm 4.5$ & $1148.6 \pm 6.5$ \\
\hline \multicolumn{6}{|c|}{ BMD measured with DXA $\left(\mathrm{g} / \mathrm{cm}^{2}\right)$} \\
\hline Total body & $0.968 \pm 0.003$ & $0.960 \pm 0.004$ & $0.965 \pm 0.011$ & $0.966 \pm 0.003$ & $0.961 \pm 0.004$ \\
\hline L2-L4 & $0.868 \pm 0.005$ & $0.861 \pm 0.006$ & $0.863 \pm 0.016$ & $0.865 \pm 0.004$ & $0.861 \pm 0.006$ \\
\hline Femoral neck & $0.683 \pm 0.003$ & $0.670 \pm 0.004^{b}$ & $0.684 \pm 0.011$ & $0.677 \pm 0.003$ & $0.671 \pm 0.004^{\mathrm{c}}$ \\
\hline Trochanter & $0.576 \pm 0.003$ & $0.564 \pm 0.004$ & $0.569 \pm 0.010$ & $0.571 \pm 0.003$ & $0.565 \pm 0.004^{\mathrm{d}}$ \\
\hline
\end{tabular}

${ }^{\mathrm{a}} \mathrm{BMD}$ is adjusted for age, height, and body weight. Data are means $\pm \mathrm{SE} .{ }^{\mathrm{b}} \mathrm{P}=0.0442,{ }^{\mathrm{c}} \mathrm{P}=0.0320,{ }^{\mathrm{d}} \mathrm{P}=0.0266$ versus $G G$. 
Table IV. BMD and other characteristics for all women $(\mathrm{n}=1106)$ according to the CNR2 genotype. ${ }^{\mathrm{a}}$

\begin{tabular}{|c|c|c|c|c|c|}
\hline Characteristic & $A A$ & $A G$ & $G G$ & $A A+A G$ & $A G+G G$ \\
\hline Number $(\%)$ & $402(36.3)$ & $544(49.2)$ & $160(14.5)$ & $946(85.5)$ & $704(63.7)$ \\
\hline Age (years) & $59.1 \pm 0.5$ & $59.1 \pm 0.5$ & $60.4 \pm 0.9$ & $59.1 \pm 0.4$ & $59.4 \pm 0.4$ \\
\hline Height $(\mathrm{cm})$ & $151.6 \pm 0.3$ & $151.4 \pm 0.3$ & $150.5 \pm 0.5$ & $151.5 \pm 0.2$ & $151.2 \pm 0.2$ \\
\hline Body weight (kg) & $52.8 \pm 0.4^{\mathrm{b}}$ & $53.0 \pm 0.4^{\mathrm{c}}$ & $51.0 \pm 0.6$ & $52.9 \pm 0.3^{\mathrm{d}}$ & $52.5 \pm 0.3$ \\
\hline \multicolumn{6}{|c|}{ BMD measured with pQCT $\left(\mathrm{mg} / \mathrm{cm}^{3}\right)$} \\
\hline D50 & $192.9 \pm 3.1^{\mathrm{e}}$ & $182.1 \pm 2.6^{\mathrm{f}}$ & $176.3 \pm 4.9$ & $186.7 \pm 2.0$ & $180.8 \pm 2.3^{\mathrm{g}}$ \\
\hline D100 & $491.4 \pm 4.5$ & $484.8 \pm 3.8$ & $476.7 \pm 7.1$ & $487.6 \pm 2.9$ & $483.0 \pm 3.4$ \\
\hline P100 & $1154.0 \pm 7.2$ & $1157.3 \pm 6.2$ & $1140.5 \pm 11.5$ & $1155.9 \pm 4.7$ & $1153.5 \pm 5.4$ \\
\hline \multicolumn{6}{|c|}{ BMD measured with DXA $\left(\mathrm{g} / \mathrm{cm}^{2}\right)$} \\
\hline Total body & $0.971 \pm 0.004^{\mathrm{h}}$ & $0.965 \pm 0.004$ & $0.952 \pm 0.007$ & $0.967 \pm 0.003^{\mathrm{i}}$ & $0.962 \pm 0.003$ \\
\hline L2-L4 & $0.876 \pm 0.006^{j}$ & $0.863 \pm 0.005$ & $0.846 \pm 0.010$ & $0.869 \pm 0.004^{\mathrm{k}}$ & $0.859 \pm 0.005^{1}$ \\
\hline Femoral neck & $0.682 \pm 0.004$ & $0.676 \pm 0.004$ & $0.673 \pm 0.007$ & $0.679 \pm 0.003$ & $0.675 \pm 0.003$ \\
\hline Trochanter & $0.575 \pm 0.004$ & $0.571 \pm 0.004$ & $0.559 \pm 0.006$ & $0.573 \pm 0.003$ & $0.569 \pm 0.003$ \\
\hline
\end{tabular}

${ }^{\mathrm{a}} \mathrm{BMD}$ is adjusted for age, height, and body weight. Data are means $\pm \mathrm{SE} .{ }^{\mathrm{b}} \mathrm{P}=0.0497,{ }^{\mathrm{c} P}=0.0218,{ }^{\mathrm{d}} \mathrm{P}=0.0070,{ }^{\mathrm{e}} \mathrm{P}=0.0118,{ }^{\mathrm{h}} \mathrm{P}=0.0449$, ${ }^{\mathrm{i}} \mathrm{P}=0.0352$, ${ }^{\mathrm{j}} \mathrm{P}=0.0352,{ }^{\mathrm{k}} \mathrm{P}=0.0412$ versus $G G$; ${ }^{\mathrm{f}} \mathrm{P}=0.0220,{ }^{\mathrm{g}} \mathrm{P}=0.0018,{ }^{\mathrm{l}} \mathrm{P}=0.0382$ versus $A A$.

the femoral neck and trochanter between individuals with the $G G$ genotype and the combined group of $G A$ and $A A$ genotypes (expressed as a percentage of the larger value) were 1.8 and $1.9 \%$, respectively. For premenopausal women, BMD for the femoral neck and that for the trochanter were greater in individuals with the $G G$ genotype than in the combined group of $G A$ and $A A$ genotypes (data not shown). For postmenopausal women or for men, there was no difference in BMD among PLOD1 genotypes (data not shown).

Relation of the $A \rightarrow G$ polymorphism of $C N R 2$ to BMD. The distribution of $\mathrm{A} \rightarrow \mathrm{G}$ genotypes of $C N R 2$ was in HardyWeinberg equilibrium, and age and height did not differ among genotypes, for all women (Table IV). Body weight was greater in women with the $A A$ genotype or the $A G$ genotype or in the combined group of $A A$ and $A G$ genotypes than in women with the $G G$ genotype. Among all women, BMD for D50 was greater in individuals with the $A A$ genotype than in those with the $A G$ genotype or the $G G$ genotype or in the combined group of $A G$ and $G G$ genotypes (Table IV). BMD for the total body and that for the lumbar spine were greater in individuals with the $A A$ genotype or in the combined group of $A A$ and $A G$ genotypes than in women with the $G G$ genotype. BMD for the lumbar spine was also greater in individuals with the $A A$ genotype than in the combined group of $A G$ and $G G$ genotypes. The differences in BMD for D50, total body, and lumbar spine between individuals with the $A A$ genotype and those with the $G G$ genotype were 8.6, 2.0, and $3.4 \%$, respectively.

The distribution of $\mathrm{A} \rightarrow \mathrm{G}$ genotypes of $C N R 2$ was in HardyWeinberg equilibrium in premenopausal (Table V) and postmenopausal (Table VI) women. Age, height, or body weight did not differ among genotypes for premenopausal or postmenopausal women. For premenopausal women, BMD for D50 was greater in individuals with the $A A$ genotype than in those with the $A G$ genotype or in the combined group of $A G$ and $G G$ genotypes (Table V). BMD for the lumbar spine was also greater in individuals with the $A A$ genotype than in the combined group of $A G$ and $G G$ genotypes. The differences in BMD for D50 and the lumbar spine between individuals with the $A A$ genotype and the combined group of $A G$ and $G G$ genotypes were 6.4 and $2.7 \%$, respectively.

For postmenopausal women, BMD for D50 was greater in individuals with the $A A$ genotype or in the combined group of $A A$ and $A G$ genotypes than in individuals with the $G G$ genotype, and was greater in individuals with the $A A$ genotype than in the combined group of $A G$ and $G G$ genotypes (Table VI). BMD for the total body and that for the trochanter were greater in the combined group of $A A$ and $A G$ genotypes than in individuals with the $G G$ genotype. The difference in BMD for D50 between individuals with the $A A$ genotype and those with the $G G$ genotype was $10.1 \%$, and those for the total body and trochanter between the combined group of $A A$ and $A G$ genotypes and individuals with the $G G$ genotype were 2.1 and $2.8 \%$, respectively.

For men, the distribution of $\mathrm{A} \rightarrow \mathrm{G}$ genotypes of $C N R 2$ was in Hardy-Weinberg equilibrium, and BMD for the total body, femoral neck, or trochanter was greater in the combined group of $A G$ and $G G$ genotypes than in individuals with the $A A$ genotype (data not shown).

Relation of the 1019C $\rightarrow T$ (Pro319Ser) polymorphism of GJA4 to BMD. The distribution of $1019 \mathrm{C} \rightarrow \mathrm{T}$ genotypes of GJA4 was in Hardy-Weinberg equilibrium, and BMD for the femoral neck was greater in individuals with the $C T$ genotype or in the combined group of $C T$ and $T T$ genotypes than in individuals with the $C C$ genotype, for all women and for postmenopausal women (data not shown). For premenopausal women, there was no difference in BMD among GJA4 genotypes (data not shown). 
Table V. BMD and other characteristics for premenopausal women $(\mathrm{n}=276)$ according to the $C N R 2$ genotype. ${ }^{\mathrm{a}}$

\begin{tabular}{|c|c|c|c|c|c|}
\hline Characteristic & $A A$ & $A G$ & $G G$ & $A A+A G$ & $A G+G G$ \\
\hline Number $(\%)$ & $106(38.4)$ & $140(50.7)$ & $30(10.9)$ & $246(89.1)$ & $170(61.6)$ \\
\hline Age (years) & $46.8 \pm 0.4$ & $46.1 \pm 0.4$ & $44.8 \pm 0.8$ & $46.4 \pm 0.3$ & $45.9 \pm 0.4$ \\
\hline Height $(\mathrm{cm})$ & $154.3 \pm 0.5$ & $154.6 \pm 0.4$ & $154.3 \pm 0.9$ & $154.5 \pm 0.3$ & $154.5 \pm 0.4$ \\
\hline Body weight (kg) & $54.7 \pm 0.8$ & $54.6 \pm 0.7$ & $52.0 \pm 1.5$ & $54.6 \pm 0.5$ & $54.1 \pm 0.6$ \\
\hline \multicolumn{6}{|c|}{ BMD measured with pQCT $\left(\mathrm{mg} / \mathrm{cm}^{3}\right)$} \\
\hline D50 & $255.7 \pm 5.4$ & $237.8 \pm 4.6^{\mathrm{b}}$ & $246.4 \pm 10.1$ & $245.3 \pm 3.6$ & $239.3 \pm 4.2^{\mathrm{c}}$ \\
\hline D100 & $614.5 \pm 7.7$ & $598.7 \pm 6.6$ & $612.3 \pm 14.3$ & $605.4 \pm 5.0$ & $601.1 \pm 6.0$ \\
\hline P100 & $1366.3 \pm 11.4$ & $1354.0 \pm 9.7$ & $1370.9 \pm 21.2$ & $1359.2 \pm 7.4$ & $1356.9 \pm 8.8$ \\
\hline \multicolumn{6}{|c|}{ BMD measured with DXA $\left(\mathrm{g} / \mathrm{cm}^{2}\right)$} \\
\hline Total body & $1.102 \pm 0.008$ & $1.085 \pm 0.007$ & $1.100 \pm 0.015$ & $1.092 \pm 0.005$ & $1.088 \pm 0.006$ \\
\hline L2-L4 & $1.042 \pm 0.011$ & $1.011 \pm 0.010$ & $1.027 \pm 0.021$ & $1.024 \pm 0.007$ & $1.014 \pm 0.009^{\mathrm{d}}$ \\
\hline Femoral neck & $0.776 \pm 0.009$ & $0.763 \pm 0.008$ & $0.790 \pm 0.016$ & $0.769 \pm 0.006$ & $0.768 \pm 0.007$ \\
\hline Trochanter & $0.666 \pm 0.008$ & $0.652 \pm 0.007$ & $0.659 \pm 0.015$ & $0.658 \pm 0.005$ & $0.653 \pm 0.006$ \\
\hline
\end{tabular}

${ }^{\mathrm{a}} \mathrm{BMD}$ is adjusted for age, height, and body weight. Data are means $\pm \mathrm{SE} .{ }^{\mathrm{b}} \mathrm{P}=0.0334,{ }^{\mathrm{c}} \mathrm{P}=0.0173,{ }^{\mathrm{d}} \mathrm{P}=0.0480$ versus $A A$.

Table VI. BMD and other characteristics for postmenopausal women $(\mathrm{n}=813)$ according to the $C N R 2$ genotype. ${ }^{\mathrm{a}}$

\begin{tabular}{|c|c|c|c|c|c|}
\hline Characteristic & $A A$ & $A G$ & $G G$ & $A A+A G$ & $A G+G G$ \\
\hline Number $(\%)$ & $291(35.8)$ & $393(48.3)$ & $129(15.9)$ & $684(84.1)$ & $522(64.2)$ \\
\hline Age (years) & $63.7 \pm 0.5$ & $63.9 \pm 0.4$ & $64.1 \pm 0.8$ & $63.8 \pm 0.3$ & $64.0 \pm 0.4$ \\
\hline Height (cm) & $150.5 \pm 0.4$ & $150.1 \pm 0.3$ & $149.6 \pm 0.5$ & $150.3 \pm 0.2$ & $150.0 \pm 0.3$ \\
\hline Body weight (kg) & $52.1 \pm 0.5$ & $52.3 \pm 0.4$ & $50.9 \pm 0.7$ & $52.2 \pm 0.3$ & $52.0 \pm 0.4$ \\
\hline \multicolumn{6}{|c|}{ BMD measured with pQCT $\left(\mathrm{mg} / \mathrm{cm}^{3}\right)$} \\
\hline D50 & $170.9 \pm 3.7^{\mathrm{b}}$ & $161.9 \pm 3.2$ & $153.6 \pm 5.6$ & $165.7 \pm 2.5^{\mathrm{c}}$ & $159.8 \pm 2.8^{\mathrm{d}}$ \\
\hline D100 & $447.3 \pm 5.4$ & $443.9 \pm 4.6$ & $434.0 \pm 8.1$ & $445.4 \pm 3.5$ & $441.5 \pm 4.0$ \\
\hline P100 & $1078.2 \pm 8.9$ & $1086.4 \pm 7.6$ & $1066.4 \pm 13.5$ & $1082.9 \pm 5.8$ & $1081.5 \pm 6.6$ \\
\hline \multicolumn{6}{|c|}{ BMD measured with DXA $\left(\mathrm{g} / \mathrm{cm}^{2}\right)$} \\
\hline Total body & $0.924 \pm 0.005$ & $0.921 \pm 0.004$ & $0.903 \pm 0.008$ & $0.922 \pm 0.003^{\mathrm{e}}$ & $0.917 \pm 0.004$ \\
\hline L2-L4 & $0.817 \pm 0.007$ & $0.810 \pm 0.006$ & $0.789 \pm 0.011$ & $0.813 \pm 0.005$ & $0.805 \pm 0.006$ \\
\hline Femoral neck & $0.649 \pm 0.005$ & $0.644 \pm 0.004$ & $0.635 \pm 0.007$ & $0.646 \pm 0.003$ & $0.642 \pm 0.004$ \\
\hline Trochanter & $0.542 \pm 0.005$ & $0.543 \pm 0.004$ & $0.527 \pm 0.007$ & $0.542 \pm 0.003^{\mathrm{f}}$ & $0.539 \pm 0.004$ \\
\hline
\end{tabular}

${ }^{\mathrm{a}} \mathrm{BMD}$ is adjusted for age, height, and body weight. Data are means $\pm \mathrm{SE} .{ }^{\mathrm{b}} \mathrm{P}=0.0290,{ }^{\mathrm{c}} \mathrm{P}=0.0497,{ }^{\mathrm{e}} \mathrm{P}=0.0237,{ }^{\mathrm{f}} \mathrm{P}=0.0445$ versus $G G$; ${ }^{\mathrm{d}} \mathrm{P}=0.0179$ versus $A A$.

The distribution of $1019 \mathrm{C} \rightarrow \mathrm{T}$ genotypes of GJA4 was in Hardy-Weinberg equilibrium, and age, height, or body weight did not differ among genotypes for men (Table VII). BMD for the total body was greater in individuals with the $C T$ genotype or in the combined group of $C C$ and $C T$ genotypes than in individuals with the $T T$ genotype. BMD for the lumbar spine and that for the femoral neck were greater in individuals with the $C C$ genotype or the $C T$ genotype or in the combined group of $C C$ and $C T$ genotypes than in individuals with the $T T$ genotype. BMD for the trochanter was also greater in the combined group of $C C$ and $C T$ genotypes than in individuals with the TT genotype. The differences in BMD for the total body, lumbar spine, femoral neck, and trochanter between the combined group of $C C$ and $C T$ genotypes and individuals with the $T T$ genotype were $3.1,8.3,6.4$, and $4.6 \%$, respectively.

Relation of the $1583 G \rightarrow A$ (Arg528Lys) polymorphism of $A L A P$ to $B M D$. The distribution of $1583 \mathrm{G} \rightarrow \mathrm{A}$ genotypes of $A L A P$ was in Hardy-Weinberg equilibrium, and age, height, and body weight did not differ among genotypes, for all women, premenopausal women (Table VIII), or postmenopausal women. For premenopausal women, BMD for the total body, femoral neck, or trochanter was greater in individuals with the $G G$ genotype than in the combined group of $G A$ and $A A$ genotypes (Table VIII). The differences in BMD for the total body, femoral neck, and trochanter between individuals with the $G G$ genotype and the combined 
Table VII. BMD and other characteristics for all men $(\mathrm{n}=1128)$ according to the GJA4 genotype. ${ }^{\mathrm{a}}$

\begin{tabular}{|c|c|c|c|c|c|}
\hline Characteristic & $\mathrm{CC}$ & CT & TT & $\mathrm{CC}+\mathrm{CT}$ & $\mathrm{CT}+\mathrm{TT}$ \\
\hline Number $(\%)$ & 729 (64.6) & 357 (31.7) & $42(3.7)$ & $1086(96.3)$ & $399(35.4)$ \\
\hline Age (years) & $59.2 \pm 0.4$ & $59.0 \pm 0.6$ & $61.0 \pm 1.7$ & $59.1 \pm 0.3$ & $59.2 \pm 0.5$ \\
\hline Height $(\mathrm{cm})$ & $164.5 \pm 0.2$ & $164.8 \pm 0.3$ & $164.8 \pm 1.0$ & $164.6 \pm 0.2$ & $164.8 \pm 0.3$ \\
\hline Body weight (kg) & $62.4 \pm 0.3$ & $62.6 \pm 0.5$ & $61.5 \pm 1.4$ & $62.5 \pm 0.3$ & $62.5 \pm 0.5$ \\
\hline \multicolumn{6}{|c|}{ BMD measured with pQCT $\left(\mathrm{mg} / \mathrm{cm}^{3}\right)$} \\
\hline D50 & $266.3 \pm 2.5$ & $268.7 \pm 3.5$ & $257.3 \pm 10.3$ & $267.1 \pm 2.0$ & $267.5 \pm 3.3$ \\
\hline D100 & $541.2 \pm 3.4$ & $541.9 \pm 4.9$ & $533.4 \pm 14.2$ & $541.4 \pm 2.8$ & $541.0 \pm 4.6$ \\
\hline P100 & $1184.3 \pm 5.2$ & $1188.0 \pm 7.4$ & $1185.8 \pm 21.6$ & $1185.5 \pm 4.2$ & $1187.8 \pm 7.0$ \\
\hline \multicolumn{6}{|c|}{ BMD measured with DXA $\left(\mathrm{g} / \mathrm{cm}^{2}\right)$} \\
\hline Total body & $1.087 \pm 0.003$ & $1.091 \pm 0.005^{\mathrm{b}}$ & $1.055 \pm 0.014$ & $1.089 \pm 0.003^{\mathrm{c}}$ & $1.087 \pm 0.005$ \\
\hline L2-L4 & $0.987 \pm 0.006^{\mathrm{d}}$ & $0.983 \pm 0.008^{\mathrm{e}}$ & $0.904 \pm 0.023$ & $0.986 \pm 0.005^{f}$ & $0.975 \pm 0.007$ \\
\hline Femoral neck & $0.754 \pm 0.004^{\mathrm{g}}$ & $0.758 \pm 0.005^{\mathrm{h}}$ & $0.707 \pm 0.015$ & $0.755 \pm 0.003^{\mathrm{i}}$ & $0.753 \pm 0.005$ \\
\hline Trochanter & $0.669 \pm 0.004$ & $0.671 \pm 0.005$ & $0.639 \pm 0.015$ & $0.670 \pm 0.003^{j}$ & $0.668 \pm 0.005$ \\
\hline
\end{tabular}

${ }^{\mathrm{a} B M D}$ is adjusted for age, height, and body weight. Data are means $\pm \mathrm{SE} .{ }^{\mathrm{b}} \mathrm{P}=0.0370,{ }^{\mathrm{c}} \mathrm{P}=0.0181,{ }^{\mathrm{d}} \mathrm{P}=0.0011,{ }^{\mathrm{e}} \mathrm{P}=0.0029,{ }^{\mathrm{f}} \mathrm{P}=0.0004,{ }^{\mathrm{g}} \mathrm{P}=0.0085$, hP=0.0042, ${ }^{\mathrm{P}} \mathrm{P}=0.0020,{ }^{\mathrm{j}} \mathrm{P}=0.0446$ versus $T T$.

Table VIII. BMD and other characteristics for premenopausal women $(\mathrm{n}=276)$ according to the $A L A P$ genotype. ${ }^{\mathrm{a}}$

\begin{tabular}{|c|c|c|c|c|c|}
\hline Characteristic & $G G$ & $G A$ & $A A$ & $G G+G A$ & $G A+A A$ \\
\hline Number $(\%)$ & $80(29.0)$ & $127(46.0)$ & $69(25.0)$ & $207(75.0)$ & $196(71.0)$ \\
\hline Age (years) & $46.4 \pm 0.5$ & $45.9 \pm 0.4$ & $46.7 \pm 0.6$ & $46.1 \pm 0.3$ & $46.2 \pm 0.3$ \\
\hline Height $(\mathrm{cm})$ & $154.5 \pm 0.5$ & $154.3 \pm 0.4$ & $154.6 \pm 0.6$ & $154.4 \pm 0.3$ & $154.4 \pm 0.3$ \\
\hline Body weight $(\mathrm{kg})$ & $54.2 \pm 0.9$ & $54.8 \pm 0.7$ & $53.5 \pm 1.0$ & $54.6 \pm 0.6$ & $54.4 \pm 0.6$ \\
\hline \multicolumn{6}{|c|}{ BMD measured with pQCT $\left(\mathrm{mg} / \mathrm{cm}^{3}\right)$} \\
\hline D50 & $250.7 \pm 6.2$ & $241.8 \pm 5.0$ & $247.6 \pm 6.6$ & $245.3 \pm 3.9$ & $243.9 \pm 4.0$ \\
\hline D100 & $609.9 \pm 8.7$ & $603.4 \pm 7.0$ & $607.5 \pm 9.4$ & $605.9 \pm 5.5$ & $604.9 \pm 5.6$ \\
\hline P100 & $1357.1 \pm 12.9$ & $1359.2 \pm 10.4$ & $1370.7 \pm 13.9$ & $1358.4 \pm 8.1$ & $1363.3 \pm 8.3$ \\
\hline \multicolumn{6}{|c|}{ BMD measured with DXA $\left(\mathrm{g} / \mathrm{cm}^{2}\right)$} \\
\hline Total body & $1.113 \pm 0.009$ & $1.086 \pm 0.007$ & $1.085 \pm 0.010$ & $1.097 \pm 0.006$ & $1.086 \pm 0.006^{\mathrm{b}}$ \\
\hline L2-L4 & $1.036 \pm 0.013$ & $1.017 \pm 0.010$ & $1.024 \pm 0.014$ & $1.025 \pm 0.008$ & $1.020 \pm 0.008$ \\
\hline Femoral neck & $0.789 \pm 0.010$ & $0.761 \pm 0.008$ & $0.771 \pm 0.011$ & $0.772 \pm 0.006$ & $0.764 \pm 0.006^{c}$ \\
\hline Trochanter & $0.676 \pm 0.009$ & $0.653 \pm 0.007$ & $0.646 \pm 0.010$ & $0.662 \pm 0.006$ & $0.650 \pm 0.006^{\mathrm{d}}$ \\
\hline
\end{tabular}

aBMD is adjusted for age, height, and body weight. Data are means $\pm \mathrm{SE} .{ }^{\mathrm{b}} \mathrm{P}=0.0107,{ }^{\mathrm{c}} \mathrm{P}=0.0380,{ }^{\mathrm{d}} \mathrm{P}=0.0191$ versus $G G$.

group of $G A$ and $A A$ genotypes were $2.4,3.2$, and $3.8 \%$, respectively. There was no difference in BMD among ALAP genotypes for all women or postmenopausal women (data not shown).

For men, the distribution of $1583 \mathrm{G} \rightarrow \mathrm{A}$ genotypes of $A L A P$ was in Hardy-Weinberg equilibrium, and BMD for the femoral neck was greater in individuals with the $G G$ genotype than in those with the $G A$ genotype or in the combined group of $G A$ and $A A$ genotypes (data not shown).

Relation of the $-514 C \rightarrow T$ polymorphism of $L I P C$ to BMD. The distribution of $-514 \mathrm{C} \rightarrow \mathrm{T}$ genotypes of LIPC was in HardyWeinberg equilibrium, and age, height, and body weight did not differ among genotypes, for all women (Table IX), premenopausal women, or postmenopausal women (Table X). For all women, BMD for D50 was greater in the combined group of $C C$ and $C T$ genotypes than in individuals with the TT genotype (Table IX). BMD for the total body was greater in individuals with the $C T$ genotype than in those with the $C C$ genotype or the $T T$ genotype, and was greater in the combined group of $C C$ and $C T$ genotypes than in individuals with the $T T$ genotype. BMD for the trochanter was greater in individuals with the $C T$ genotype or in the combined group of $C C$ and $C T$ genotypes than in individuals with the $T T$ genotype. The differences in BMD for D50, total body, and trochanter between the combined group of $C C$ and $C T$ geno- 
Table IX. BMD and other characteristics for all women $(\mathrm{n}=1110)$ according to the LIPC genotype. ${ }^{\mathrm{a}}$

\begin{tabular}{|c|c|c|c|c|c|}
\hline Characteristic & $C C$ & $C T$ & $T T$ & $C C+C T$ & $C T+T T$ \\
\hline Number $(\%)$ & $250(22.5)$ & $558(50.3)$ & $302(27.2)$ & $808(72.8)$ & $860(77.5)$ \\
\hline Age (years) & $59.2 \pm 0.7$ & $59.3 \pm 0.5$ & $59.2 \pm 0.6$ & $59.3 \pm 0.4$ & $59.3 \pm 0.4$ \\
\hline Height (cm) & $151.2 \pm 0.4$ & $151.3 \pm 0.3$ & $151.4 \pm 0.3$ & $151.3 \pm 0.2$ & $151.4 \pm 0.2$ \\
\hline Body weight (kg) & $52.7 \pm 0.5$ & $52.6 \pm 0.3$ & $52.6 \pm 0.5$ & $52.6 \pm 0.3$ & $52.6 \pm 0.3$ \\
\hline \multicolumn{6}{|c|}{ BMD measured with pQCT $\left(\mathrm{mg} / \mathrm{cm}^{3}\right)$} \\
\hline D50 & $186.2 \pm 3.9$ & $188.3 \pm 2.6$ & $178.6 \pm 3.5$ & $187.6 \pm 2.2^{\mathrm{b}}$ & $184.8 \pm 2.1$ \\
\hline D100 & $485.9 \pm 5.6$ & $490.1 \pm 3.8$ & $478.2 \pm 5.1$ & $488.8 \pm 3.1$ & $485.9 \pm 3.1$ \\
\hline P100 & $1148.2 \pm 9.1$ & $1159.1 \pm 6.1$ & $1149.2 \pm 8.3$ & $1155.7 \pm 5.1$ & $1155.6 \pm 4.9$ \\
\hline \multicolumn{6}{|c|}{ BMD measured with DXA $\left(\mathrm{g} / \mathrm{cm}^{2}\right)$} \\
\hline Total body & $0.956 \pm 0.005$ & $0.974 \pm 0.004^{\mathrm{c}, \mathrm{d}}$ & $0.956 \pm 0.005$ & $0.968 \pm 0.003^{\mathrm{e}}$ & $0.968 \pm 0.003$ \\
\hline L2-L4 & $0.859 \pm 0.008$ & $0.873 \pm 0.005$ & $0.856 \pm 0.007$ & $0.869 \pm 0.004$ & $0.867 \pm 0.004$ \\
\hline Femoral neck & $0.674 \pm 0.005$ & $0.681 \pm 0.004$ & $0.675 \pm 0.005$ & $0.679 \pm 0.003$ & $0.679 \pm 0.003$ \\
\hline Trochanter & $0.568 \pm 0.005$ & $0.577 \pm 0.003^{\mathrm{f}}$ & $0.562 \pm 0.005$ & $0.574 \pm 0.003^{\mathrm{g}}$ & $0.572 \pm 0.003$ \\
\hline
\end{tabular}

${ }^{a} \mathrm{BMD}$ is adjusted for age, height, and body weight. Data are means $\pm \mathrm{SE} .{ }^{\mathrm{b}} \mathrm{P}=0.0310,{ }^{\mathrm{d}} \mathrm{P}=0.0098,{ }^{\mathrm{e}} \mathrm{P}=0.0324,{ }^{\mathrm{f}} \mathrm{P}=0.0353$, ${ }^{\mathrm{g}} \mathrm{P}=0.0317$ versus $T T$; ${ }^{\mathrm{c}} \mathrm{P}=0.0176$ versus $C C$.

Table X. BMD and other characteristics for postmenopausal women $(\mathrm{n}=815)$ according to the LIPC genotype.

\begin{tabular}{|c|c|c|c|c|c|}
\hline Characteristic & $C C$ & $C T$ & $T T$ & $C C+C T$ & $C T+T T$ \\
\hline Number $(\%)$ & $181(22.2)$ & $406(49.8)$ & $228(28.0)$ & $587(72.0)$ & $634(77.8)$ \\
\hline Age (years) & $64.2 \pm 0.6$ & $64.1 \pm 0.4$ & $63.3 \pm 0.6$ & $64.1 \pm 0.4$ & $63.8 \pm 0.3$ \\
\hline Height $(\mathrm{cm})$ & $149.7 \pm 0.5$ & $150.3 \pm 0.3$ & $150.3 \pm 0.4$ & $150.1 \pm 0.3$ & $150.3 \pm 0.2$ \\
\hline Body weight (kg) & $52.2 \pm 0.6$ & $51.7 \pm 0.4$ & $52.4 \pm 0.5$ & $51.8 \pm 0.4$ & $52.0 \pm 0.3$ \\
\hline \multicolumn{6}{|c|}{ BMD measured with pQCT $\left(\mathrm{mg} / \mathrm{cm}^{3}\right)$} \\
\hline D50 & $164.7 \pm 4.7$ & $167.6 \pm 3.2$ & $156.1 \pm 4.2$ & $166.7 \pm 2.6^{\mathrm{b}}$ & $163.4 \pm 2.5$ \\
\hline D100 & $442.3 \pm 6.8$ & $447.7 \pm 4.6$ & $436.2 \pm 6.0$ & $446.1 \pm 3.8$ & $443.6 \pm 3.6$ \\
\hline P100 & $1073.7 \pm 11.3$ & $1087.7 \pm 7.5$ & $1071.3 \pm 10.0$ & $1083.4 \pm 6.3$ & $1081.8 \pm 6.0$ \\
\hline \multicolumn{6}{|c|}{ BMD measured with DXA $\left(\mathrm{g} / \mathrm{cm}^{2}\right)$} \\
\hline Total body & $0.907 \pm 0.006$ & $0.929 \pm 0.004^{\mathrm{c}, \mathrm{d}}$ & $0.911 \pm 0.006$ & $0.922 \pm 0.004$ & $0.922 \pm 0.003^{\mathrm{e}}$ \\
\hline L2-L4 & $0.799 \pm 0.010$ & $0.818 \pm 0.006$ & $0.801 \pm 0.008$ & $0.812 \pm 0.005$ & $0.812 \pm 0.005$ \\
\hline Femoral neck & $0.639 \pm 0.006$ & $0.649 \pm 0.004$ & $0.641 \pm 0.006$ & $0.646 \pm 0.003$ & $0.646 \pm 0.003$ \\
\hline Trochanter & $0.537 \pm 0.006$ & $0.545 \pm 0.004$ & $0.533 \pm 0.005$ & $0.543 \pm 0.003$ & $0.541 \pm 0.003$ \\
\hline
\end{tabular}

${ }^{\mathrm{a}} \mathrm{BMD}$ is adjusted for age, height, and body weight. Data are means $\pm \mathrm{SE}$. ${ }^{\mathrm{C}} \mathrm{P}=0.0334,{ }^{\mathrm{d}} \mathrm{P}=0.0348$ versus $T T ;{ }^{\mathrm{C}} \mathrm{P}=0.0173,{ }^{\mathrm{e}} \mathrm{P}=0.0439$ versus $C C$.

types and individuals with the $T T$ genotype were $4.8,1.2$, and $2.1 \%$, respectively.

For postmenopausal women, BMD for D50 was greater in the combined group of $C C$ and $C T$ genotypes than in individuals with the $T T$ genotype (Table X). BMD for the total body was greater in individuals with the $C T$ genotype than in those with the $C C$ genotype or the $T T$ genotype, and was greater in the combined group of $C T$ and $T T$ genotypes than in individuals with the $C C$ genotype. The difference in BMD for D50 between the combined group of $C C$ and $C T$ genotypes and individuals with the $T T$ genotype and that for the total body between the combined group of $C T$ and $T T$ genotypes and individuals with the $C C$ genotype were 6.4 and $1.6 \%$, respectively.
For premenopausal women or men, no relation was detected between LIPC genotype and BMD (data not shown).

Relation of the $1462 A \rightarrow G$ (Lys469Glu) polymorphism of ICAM1 to BMD. The distribution of $1462 \mathrm{~A} \rightarrow \mathrm{G}$ genotypes of ICAMI was in Hardy-Weinberg equilibrium, and age and height did not differ among genotypes for all women (Table XI), premenopausal women, or postmenopausal women (Table XII). For all women and postmenopausal women, but not premenopausal women, body weight was greater in individuals with the $G G$ genotype than in the combined group of $A A$ and $A G$ genotypes. For all women, BMD for D50 was greater in individuals with the $G G$ genotype than in those with the $A A$ genotype or in the combined group of $A A$ and 
Table XI. BMD and other characteristics for all women (n=1096) according to the ICAMI genotype. ${ }^{\mathrm{a}}$

\begin{tabular}{|c|c|c|c|c|c|}
\hline Characteristic & AA & $\mathrm{AG}$ & GG & $\mathrm{AA}+\mathrm{AG}$ & $\mathrm{AG}+\mathrm{GG}$ \\
\hline Number (\%) & $364(33.2)$ & $536(48.9)$ & $196(17.9)$ & $900(82.1)$ & $732(66.8)$ \\
\hline Age (years) & $60.0 \pm 0.6$ & $58.9 \pm 0.5$ & $59.1 \pm 0.8$ & $59.3 \pm 0.4$ & $59.0 \pm 0.4$ \\
\hline Height (cm) & $151.1 \pm 0.3$ & $151.3 \pm 0.3$ & $151.7 \pm 0.4$ & $151.2 \pm 0.2$ & $151.4 \pm 0.2$ \\
\hline Body weight (kg) & $52.3 \pm 0.4$ & $52.4 \pm 0.4$ & $53.9 \pm 0.6$ & $52.3 \pm 0.3^{\mathrm{b}}$ & $52.8 \pm 0.3$ \\
\hline \multicolumn{6}{|c|}{ BMD measured with pQCT $\left(\mathrm{mg} / \mathrm{cm}^{3}\right)$} \\
\hline D50 & $177.6 \pm 3.2^{\mathrm{c}}$ & $186.6 \pm 2.7$ & $194.9 \pm 4.4$ & $182.9 \pm 2.1^{\mathrm{d}}$ & $188.8 \pm 2.3^{\mathrm{e}}$ \\
\hline D100 & $481.8 \pm 4.6^{\mathrm{f}}$ & $483.1 \pm 3.9^{\mathrm{g}}$ & $500.8 \pm 6.4$ & $482.6 \pm 3.0^{\mathrm{h}}$ & $487.9 \pm 3.3$ \\
\hline P100 & $1143.5 \pm 7.5$ & $1154.3 \pm 6.2$ & $1169.9 \pm 10.3$ & $1149.9 \pm 4.8$ & $1158.5 \pm 5.3$ \\
\hline \multicolumn{6}{|c|}{ BMD measured with DXA $\left(\mathrm{g} / \mathrm{cm}^{2}\right)$} \\
\hline Total body & $0.960 \pm 0.004$ & $0.965 \pm 0.004$ & $0.973 \pm 0.006$ & $0.963 \pm 0.003$ & $0.967 \pm 0.003$ \\
\hline L2-L4 & $0.856 \pm 0.007$ & $0.870 \pm 0.006$ & $0.869 \pm 0.009$ & $0.864 \pm 0.004$ & $0.870 \pm 0.005$ \\
\hline Femoral neck & $0.677 \pm 0.004$ & $0.677 \pm 0.004$ & $0.679 \pm 0.006$ & $0.677 \pm 0.003$ & $0.678 \pm 0.003$ \\
\hline Trochanter & $0.564 \pm 0.004$ & $0.574 \pm 0.004$ & $0.576 \pm 0.006$ & $0.570 \pm 0.003$ & $0.574 \pm 0.003$ \\
\hline
\end{tabular}

${ }^{\mathrm{a}} \mathrm{BMD}$ is adjusted for age, height, and body weight. Data are means $\pm \mathrm{SE} .{ }^{\mathrm{b}} \mathrm{P}=0.0148,{ }^{\mathrm{c}} \mathrm{P}=0.0046,{ }^{\mathrm{d}} \mathrm{P}=0.0142,{ }^{\mathrm{f}} \mathrm{P}=0.0439,{ }^{\mathrm{g}} \mathrm{P}=0.0489,{ }^{\mathrm{h}} \mathrm{P}=0.0101$ versus $G G$; ${ }^{\mathrm{e}} \mathrm{P}=0.0046$ versus $A A$.

Table XII. BMD and other characteristics for postmenopausal women (n=807) according to the ICAMI genotype. ${ }^{\mathrm{a}}$

\begin{tabular}{|c|c|c|c|c|c|}
\hline Characteristic & $A A$ & $A G$ & $G G$ & $A A+A G$ & $\mathrm{~A} G+G G$ \\
\hline Number $(\%)$ & $274(34.0)$ & $386(47.8)$ & $147(18.2)$ & $660(81.8)$ & $533(66.0)$ \\
\hline Age (years) & $64.3 \pm 0.5$ & $63.9 \pm 0.4$ & $63.1 \pm 0.7$ & $64.1 \pm 0.3$ & $63.7 \pm 0.4$ \\
\hline Height $(\mathrm{cm})$ & $150.0 \pm 0.4$ & $150.0 \pm 0.3$ & $150.8 \pm 0.5$ & $150.0 \pm 0.2$ & $150.2 \pm 0.3$ \\
\hline Body weight (kg) & $51.6 \pm 0.5$ & $51.7 \pm 0.4$ & $53.5 \pm 0.7$ & $51.7 \pm 0.3^{\mathrm{b}}$ & $52.2 \pm 0.4$ \\
\hline \multicolumn{6}{|c|}{ BMD measured with pQCT $\left(\mathrm{mg} / \mathrm{cm}^{3}\right)$} \\
\hline D50 & $156.3 \pm 3.8^{\mathrm{c}}$ & $163.9 \pm 3.3$ & $176.0 \pm 5.2$ & $160.7 \pm 2.5^{\mathrm{d}}$ & $167.3 \pm 2.8^{\mathrm{e}}$ \\
\hline D100 & $438.1 \pm 5.5$ & $440.3 \pm 4.7$ & $459.4 \pm 7.5$ & $439.3 \pm 3.6^{\mathrm{f}}$ & $445.6 \pm 4.0$ \\
\hline P100 & $1068.4 \pm 9.1$ & $1080.4 \pm 7.8$ & $1097.6 \pm 12.5$ & $1075.3 \pm 5.9$ & $1085.2 \pm 6.6$ \\
\hline \multicolumn{6}{|c|}{ BMD measured with DXA $\left(\mathrm{g} / \mathrm{cm}^{2}\right)$} \\
\hline Total body & $0.910 \pm 0.005^{\mathrm{g}}$ & $0.919 \pm 0.004$ & $0.936 \pm 0.007$ & $0.915 \pm 0.003^{\mathrm{h}}$ & $0.923 \pm 0.004^{\mathrm{i}}$ \\
\hline L2-L4 & $0.796 \pm 0.008$ & $0.813 \pm 0.007$ & $0.823 \pm 0.011$ & $0.806 \pm 0.005$ & $0.816 \pm 0.006^{j}$ \\
\hline Femoral neck & $0.639 \pm 0.005$ & $0.645 \pm 0.004$ & $0.652 \pm 0.007$ & $0.643 \pm 0.003$ & $0.647 \pm 0.004$ \\
\hline Trochanter & $0.531 \pm 0.005^{\mathrm{k}}$ & $0.543 \pm 0.004$ & $0.551 \pm 0.007$ & $0.538 \pm 0.003$ & $0.545 \pm 0.004^{1}$ \\
\hline
\end{tabular}

${ }^{\mathrm{a}} \mathrm{BMD}$ is adjusted for age, height, and body weight. Data are means $\pm \mathrm{SE} .{ }^{\mathrm{b}} \mathrm{P}=0.0147,{ }^{\mathrm{c}} \mathrm{P}=0.0068,{ }^{\mathrm{d}} \mathrm{P}=0.0083,{ }^{\mathrm{f}} \mathrm{P}=0.0166,{ }^{\mathrm{g}} \mathrm{P}=0.0073$, ${ }^{\mathrm{h}} \mathrm{P}=0.0066$, ${ }^{\mathrm{k}} \mathrm{P}=0.0436$ versus $G G ;{ }^{\mathrm{e}} \mathrm{P}=0.0205,{ }^{\mathrm{i}} \mathrm{P}=0.0319,{ }^{\mathrm{j}} \mathrm{P}=0.0441,{ }^{\mathrm{P}} \mathrm{P}=0.0220$ versus $A A$.

$A G$ genotypes, and was greater in the combined group of $A G$ and $G G$ genotypes than in individuals with the $A A$ genotype (Table XI). BMD for D100 was greater in individuals with the $G G$ genotype than in those with the $A A$ genotype or the $A G$ genotype or in the combined group of $A A$ and $A G$ genotypes. The differences in BMD for D50 and D100 between individuals with the $G G$ genotype and those with the $A A$ genotype were 8.9 and $3.8 \%$, respectively.

For postmenopausal women, BMD for D50 and that for the total body were greater in individuals with the $G G$ genotype than in those with the $A A$ genotype or in the combined group of $A A$ and $A G$ genotypes, and were greater in the combined group of $A G$ and $G G$ genotypes than in individuals with the $A A$ genotype (Table XII). BMD for D100 was greater in individuals with the $G G$ genotype than in the combined group of $A A$ and $A G$ genotypes. BMD for the lumbar spine was greater in the combined group of $A G$ and $G G$ genotypes than in individuals with the $A A$ genotype. BMD for the trochanter was greater in individuals with the $G G$ genotype or in the combined group of $A G$ and $G G$ genotypes than in individuals with the $A A$ genotype. The differences in BMD for D50, total body, and trochanter between individuals with the $G G$ genotype and those with the $A A$ genotype were 11.2 , 2.8 , and $3.6 \%$, respectively. The difference in BMD for D100 
between individuals with the $G G$ genotype and the combined group of $A A$ and $A G$ genotypes and that for the lumbar spine between the combined group of $A G$ and $G G$ genotypes and individuals with the $A A$ genotype were 4.4 and $2.5 \%$, respectively. For premenopausal women, no relation was detected between ICAMI genotype and BMD.

For men, the distribution of $\mathrm{A} \rightarrow \mathrm{G}$ genotypes of $I C A M 1$ was in Hardy-Weinberg equilibrium, and BMD for P100 was greater in the combined group of $A A$ and $A G$ genotypes than in individuals with the $G G$ genotype (data not shown).

\section{Discussion}

We have examined the relations of six candidate gene polymorphisms to BMD at various sites in communitydwelling Japanese women and men. Our results showed that the polymorphisms of ALAP and PLODI were associated with BMD in premenopausal women; those of ICAMI and LIPC with BMD in postmenopausal women; that of CNR2 with BMD in premenopausal and postmenopausal women; and that of GJA4 with BMD in men. Among these polymorphisms, those of ICAM1, CNR2, and GJA4 were markedly associated with BMD. These observations thus suggest that ALAP, PLOD1, ICAM1, LIPC, and CNR2 are susceptibility loci for reduced bone mass in Japanese women and that GJA4 constitutes such a locus in Japanese men. The polymorphisms of ICAM1 and CNR2 may confer susceptibility to postmenopausal osteoporosis in women, whereas that of GJA4 may confer susceptibility to osteoporosis in men.

Association of the $386 G \rightarrow A$ (Ala99Thr) polymorphism of PLOD1 with BMD. PLODI is located within a quantitative trait locus for regulation of BMD on chromosome 1p36 (17) and is a strong candidate gene for the regulation of BMD. PLOD1 encodes the enzyme procollagen-lysine, 2oxoglutarate 5-dioxygenase, which catalyzes the hydroxylation of lysine residues during the posttranslational modification of type I collagen, the major protein of bone matrix. Tasker et al (18) detected an association between BMD for the lumbar spine and the $386 \mathrm{G} \rightarrow \mathrm{A}$ (Ala99Thr) polymorphism of PLOD1 in a population-based cohort of 678 Scottish women. Heterozygotes for this polymorphism had a reduced BMD and an increased hydroxylysylpyridinoline to lysylpyridinoline ratio compared with either group of homozygotes, suggesting a functional effect of this polymorphism on enzyme activity. Spotila et al (19) obtained evidence for an allelic association between a $\mathrm{T} \rightarrow \mathrm{G}$ polymorphism in intron 6 of PLODI and BMD for the lumbar spine. This polymorphism and the $386 \mathrm{G} \rightarrow \mathrm{A}$ (Ala99Thr) polymorphism were in complete linkage disequilibrium. We have now shown that the $386 \mathrm{G} \rightarrow \mathrm{A}$ (Ala99Thr) polymorphism of PLODI was associated with BMD for the femoral neck and trochanter for all women and premenopausal women, with the $A$ allele being associated with reduced BMD. Our present results and the previous observations $(18,19)$ thus suggest that PLOD1 may be a susceptibility gene for reduced $\mathrm{BMD}$ in women.

Association of the $A \rightarrow G$ polymorphism of CNR2 with BMD. Two cannabinoid receptors, $\mathrm{CB} 1$ and $\mathrm{CB} 2$, encoded by $C N R 1$ and $C N R 2$, respectively, are highly homologous, belong to the family of $G$ protein-coupled seven-transmembrane domain receptors, and bind and are activated by endocannabinoids. CNR 1 is expressed predominantly in the brain and peripheral neurons (20), whereas CNR2 is expressed mainly in immune cells (21). Mice with a targeted deletion of CNRI have an increased bone mass (22), whereas CNR2 knockout mice have a decreased bone mass resembling human osteoporosis (23). These mouse genetic data implicate the endocannabinoid system in the regulation of bone mass. Furthermore, given that $C N R 2$ is located at chromosomal region $1 \mathrm{p} 36$, which has been implicated in osteoporosis (17), CNR2 is a strong candidate determinant of susceptibility to osteoporosis. Karsak et al (24) detected an association of single polymorphisms and haplotypes encompassing CNR2 on chromosome $1 \mathrm{p} 36$ with osteoporosis. We have now shown that the $\mathrm{A} \rightarrow \mathrm{G}$ polymorphism of $C N R 2$ was associated with $\mathrm{BMD}$ for the distal radius, total body, and lumbar spine in all women, with BMD for the distal radius and lumbar spine in premenopausal women, and with BMD for the distal radius, total body, and trochanter in postmenopausal women, with the $G$ allele being related to reduced BMD. Our present results and the previous association study (24), as well as the observations with CB2-deficient mice (23), thus suggest that $C N R 2$ is a susceptibility gene for reduced BMD in women.

Association of the 1019C $\rightarrow$ T (Pro319Ser) polymorphism of GJA4 with BMD. Gap junction protein, $\alpha-4$ (connexin37) is a gap junction protein in the arterial endothelium and contributes to the growth and regeneration after injury of endothelial cells (25). It forms functional intercellular channels with a voltage dependence and unitary conductance properties that are distinct from those of other channels (26). The 1019C $\rightarrow \mathrm{T}$ (Pro319Ser) polymorphism of GJA4 was previously associated with myocardial infarction (16) and coronary heart disease (27), with the $T$ allele representing a risk factor for these conditions. Wong et al (28) recently showed that GJA4 protects against excessive monocyte recruitment in atherosclerosis, revealing an anti-inflammatory role for this protein in vivo. These researchers also showed that mononuclear cells expressing the 1019T (Ser319) allele of the GJA4 polymorphism exhibited stronger adhesion than those expressing the 1019C (Pro319) allele, consistent with the observations that the 1019T (Ser319) allele is associated with an increased risk of myocardial infarction (16) and coronary heart disease (27). The anti-adhesive effect of GJA4 was shown to be mediated by release of ATP into the extracellular space. GJA4 hemichannels may thus control initiation of the development of atherosclerotic plaques by regulating monocyte adhesion (28). We have now shown that the $1019 \mathrm{C} \rightarrow \mathrm{T}$ (Pro319Ser) polymorphism of GJA4 was associated with BMD for the total body, lumbar spine, femoral neck, and trochanter in men, with the $T$ allele being associated with reduced BMD. This is the first demonstration of an association of GJA4 with BMD, although the underlying molecular mechanism of the effect of this polymorphism on bone remodeling remains to be elucidated.

Association of the $1583 G \rightarrow A$ (Arg528Lys) polymorphism of $A L A P$ with $B M D$. Adipocyte-derived leucine aminopeptidase 
(ALAP) has been identified as a member of the M1 family of zinc-dependent metallopeptidases (29). ALAP was shown to catalyze the hydrolysis of a variety of bioactive peptides in vitro and to play a role in the regulation of blood pressure through inactivation of angiotensin II and generation of bradykinin (29). The $1583 \mathrm{G} \rightarrow \mathrm{A}$ (Arg528Lys) polymorphism of $A L A P$ was associated with essential hypertension, with the 1583G (Arg528) allele representing a risk factor for this condition (30). We have now shown that the $1583 \mathrm{G} \rightarrow \mathrm{A}$ (Arg528Lys) polymorphism of ALAP was associated with BMD for the total body, femoral neck, and trochanter in premenopausal women, with the $A$ allele being associated with reduced BMD. The molecular mechanism responsible for the effect of this polymorphism on bone remodeling remains to be determined.

Association of the $-514 C \rightarrow T$ polymorphism of LIPC with $B M D$. Hepatic lipase (LIPC), a glycoprotein member of the lipase superfamily, plays an important role in the metabolism and modeling of both pro- and anti-atherogenic lipoproteins. Synthesized and secreted by the liver, LIPC performs several metabolic functions, including hydrolysis of triglycerides and phospholipids, modeling of certain low-density lipoprotein (LDL)-cholesterol particles, and catabolism of high-density lipoprotein (HDL) cholesterol (31). The $-514 \mathrm{C} \rightarrow \mathrm{T}$ polymorphism of $L I P C$, which is located in the promoter region, has been shown to affect LIPC activity, with activity being decreased in carriers of the $T$ allele $(32,33)$. This polymorphism was also shown to have a significant effect on the plasma level of HDL cholesterol, with the $T$ allele being associated with increased levels $(34,35)$. A meta-analysis of 25 studies, including a total of $>24,000$ subjects, revealed significant decreases in plasma LIPC activity and increases in HDL-cholesterol levels in individuals with the $C T$ and those with the $T T$ genotype compared with those with the $C C$ genotype of the $-514 \mathrm{C} \rightarrow \mathrm{T}$ polymorphism (36). We have now shown that this polymorphism was associated with BMD for the distal radius, total body, and trochanter in all women and with BMD for the distal radius and total body in postmenopausal women, with the $C T$ genotype being associated with increased BMD. The mechanisms responsible for the associations of the $C T$ genotype both with increased plasma concentrations of HDL (36) and with increased bone mass in women (the present study) remain to be elucidated.

Association of the $1462 A \rightarrow G$ (Lys469Glu) polymorphism of ICAMI with BMD. Interactions between osteoblasts and osteoclasts are important in osteoclastogenesis, and multiple adhesion molecules, including intercellular adhesion molecule 1 (ICAM1 or CD54) $(37,38)$, are expressed on the osteoblast surface. Studies of osteoclastogenesis in coculture systems of osteoblasts and preosteoclastic cells have revealed that inhibition of the cellular interactions mediated through ICAM1 with the use of specific monoclonal antibodies inhibited osteoclast formation $(38,39)$. These studies thus demonstrated a pivotal role for ICAM1-expressing osteoblasts in the differentiation of osteoclast precursor cells into mature osteoclasts, resulting in a shift in bone homeostasis toward resorption. Indeed, the expression of ICAMI in osteoblasts was shown to be increased in osteoporotic bone
(40). The $1462 \mathrm{~A} \rightarrow \mathrm{G}$ (Lys469Glu) polymorphism of ICAM1, which is located in a region of the gene corresponding to an immunodominant epitope involved in integrin-mediated B cell adhesion and neutrophil transmigration, has been associated with a variety of proinflammatory phenotypes including transplant rejection and vasculopathy (41) as well as postoperative myocardial infarction (42). We have now shown that this polymorphism of ICAMI was associated with BMD for the distal radius in all women, and with BMD for the distal radius, total body, lumbar spine, and trochanter in postmenopausal women, with the $A$ allele being associated with reduced BMD. The association of the $1462 \mathrm{~A} \rightarrow \mathrm{G}$ (Lys469Glu) polymorphism with BMD may be attributed to the effect of this polymorphism on osteoclastogenesis and consequent bone resorption.

Limitations of the study. Given the multiple comparisons of genotypes with BMD at various sites in the present study, it is not possible to exclude potential type I errors (false positives). It is also possible that the polymorphisms associated with reduced BMD in our study were in linkage disequilibrium with other polymorphisms in the same gene or polymorphisms of nearby genes that are actually responsible for the development of this condition. Furthermore, the relevance of the polymorphisms to gene transcription or to protein structure or function and their effects on bone remodeling were not determined in the present study.

In conclusion, our present results suggest that $A L A P$, $P L O D 1, I C A M 1, L I P C$, and CNR2 are susceptibility loci for reduced BMD in Japanese women and that GJA4 constitutes such a locus in Japanese men. The polymorphisms of ICAMI and $C N R 2$ may confer susceptibility to postmenopausal osteoporosis in women, and that of GJA4 to osteoporosis in men. Determination of genotypes for these polymorphisms may prove informative for assessment of the genetic risk for reduced BMD. Given that multiple variants, each having a small effect, will likely ultimately be found to be responsible for a large fraction of the genetic component of osteoporosis, identification of additional osteoporosis susceptibility genes will allow more accurate assessment of the genetic component of this condition.

\section{Acknowledgements}

This study was supported in part by a Research Grant for Comprehensive Research on Aging and Health (H17Chojyu-039) from the Ministry of Health, Labor, and Welfare of Japan.

\section{References}

1. Kanis JA, Melton LJ III, Christiansen C, Johnston CC and Khaltaev N: The diagnosis of osteoporosis. J Bone Miner Res 9: 1137-1141, 1994.

2. Pocock NA, Eisman JA, Hopper JL, Yeates MG, Sambrook PN and Eberl S: Genetic determinations of bone mass in adults: a twin study. J Clin Invest 80: 706-710, 1987.

3. Gueguen R, Jouanny P, Guillemin F, Kuntz C, Pourel J and Siest G: Segregation analysis and variance component analysis of bone mineral density in healthy families. J Bone Miner Res 10: 2017-2022, 1995.

4. Ralston SH: Genetic determinants of susceptibility to osteoporosis. Curr Opin Pharmacol 3: 286-290, 2003. 
5. Johnson ML, Gong G, Kimberling W, Recker SM, Kimmel DB and Recker RB: Linkage of a gene causing high bone mass to human chromosome 11 (11q12-13). Am J Hum Genet 60: 1326-1332, 1997.

6. Econs MJ, Koller DL, Hui SL, et al: Confirmation of linkage to chromosome 1q for peak vertebral bone mineral density in premenopausal white women. Am J Hum Genet 74: 223-228, 2004.

7. Morrison NA, Qi JC, Tokita A, et al: Prediction of bone density from vitamin D receptor alleles. Nature 367: 284-287, 1994.

8. Uitterlinden AG, Burger H, Huang Q, et al: Relation of alleles of the collagen type $\mathrm{I} \alpha 1$ gene to bone density and the risk of osteoporotic fractures in postmenopausal women. N Engl J Med 338: 1016-1021, 1998.

9. Yamada Y, Ando F, Niino N and Shimokata H: Transforming growth factor- $\beta 1$ gene polymorphism and bone mineral density. JAMA 285: 167-168, 2001.

10. Xiong DH, Shen H, Zhao LJ, et al: Robust and comprehensive analysis of 20 osteoporosis candidate genes by very highdensity single-nucleotide polymorphism screen among 405 white nuclear families identified significant association and gene-gene interaction. J Bone Miner Res 21: 1678-1695, 2006.

11. Shimokata $\mathrm{H}$, Ando $\mathrm{F}$ and Niino $\mathrm{N}$ : A new comprehensive study on aging - the National Institute for Longevity Sciences, Longitudinal Study of Aging (NILS-LSA). J Epidemiol 10: S1-S9, 2000 .

12. Yamada $\mathrm{Y}$, Ando F, Niino $\mathrm{N}$ and Shimokata $\mathrm{H}$ : Association of polymorphisms of interleukin-6, osteocalcin, and vitamin D receptor genes, alone or in combination, with bone mineral density in community-dwelling Japanese women and men. J Clin Endocrinol Metab 88: 3372-3378, 2003.

13. Yamada Y, Ando F, Niino N and Shimokata H: Association of polymorphisms of androgen receptor and klotho genes with bone mineral density in Japanese women. J Mol Med 83: 50-57, 2005.

14. Yamada $\mathrm{Y}$, Ando $\mathrm{F}$ and Shimokata $\mathrm{H}$ : Association of a microsomal triglyceride transfer protein gene polymorphism with blood pressure in Japanese women. Int J Mol Med 17: 83-88, 2006.

15. Yamada Y, Ando F and Shimikata H: Association of polymorphisms in forkhead box $\mathrm{C} 2$ and perilipin genes with bone mineral density in community-dwelling Japanese individuals. Int J Mol Med 18: 119-127, 2006.

16. Yamada Y, Izawa H, Ichihara S, et al: Prediction of the risk of myocardial infarction from polymorphisms in candidate genes. N Engl J Med 347: 1916-1923, 2002.

17. Devoto M, Specchia C, Li HH, et al: Variance component linkage analysis indicates a QTL for femoral neck bone mineral density on chromosome 1p36. Hum Mol Genet 10: 2447-2452, 2001.

18. Tasker PN, Macdonald H, Fraser WD, Reid DM, Ralston SH and Albagha OM: Association of PLOD1 polymorphisms with bone mineral density in a population-based study of women from the UK. Osteoporos Int 17: 1078-1085, 2006.

19. Spotila LD, Rodriguez H, Koch M, et al: Association analysis of bone mineral density and single nucleotide polymorphisms in two candidate genes on chromosome $1 \mathrm{p} 36$. Calcif Tissue Int 73 : 140-146, 2003.

20. Herkenham M, Lynn AB, Little MD, et al: Cannabinoid receptor localization in brain. Proc Natl Acad Sci USA 87: 1932-1936, 1990

21. Munro S, Thomas KL and Abu-Shaar M: Molecular characterization of a peripheral receptor for cannabinoids. Nature 365: 61-65, 1993 .

22. Idris AI, van't Hof RJ, Greig IR, et al: Regulation of bone mass, bone loss and osteoclast activity by cannabinoid receptors. Nat Med 11: 774-779, 2005.

23. Ofek O, Karsak M, Leclerc N, et al: Peripheral cannabinoid receptor, CB2, regulates bone mass. Proc Natl Acad Sci USA 103: 696-701, 2006.

24. Karsak M, Cohen-Solal M, Freudenberg J, et al: Cannabinoid receptor type 2 gene is associated with human osteoporosis. Hum Mol Genet 14: 3389-3396, 2005.
25. Yeh HI, Lai YJ, Chang HM, Ko YS, Severs NJ and Tsai CH: Multiple connexin expression in regenerating arterial endothelial gap junctions. Arterioscler Thromb Vasc Biol 20: 1753-1762, 2000.

26. Reed KE, Westphale EM, Larson DM, Wang HZ, Veenstra RD and Beyer EC: Molecular cloning and functional expression of human connexin37, an endothelial cell gap junction protein. J Clin Invest 91: 997-1004, 1993.

27. Hirashiki A, Yamada Y, Murase Y, et al: Association of gene polymorphisms with coronary artery disease in low- or high-risk subjects defined by conventional risk factors. J Am Coll Cardiol 42: 1429-1437, 2003.

28. Wong CW, Christen T, Roth I, et al: Connexin37 protects against atherosclerosis by regulating monocyte adhesion. Nat Med 12: 950-954, 2006

29. Hattori A, Kitatani K, Matsumoto H, et al: Characterization of recombinant human adipocyte-derived leucine aminopeptidase expressed in Chinese hamster ovary cells. J Biochem 128: 755-762, 2000.

30. Yamamoto N, Nakayama J, Yamakawa-Kobayashi K, Hamaguchi H, Miyazaki R and Arinami T: Identification of 33 polymorphisms in the adipocyte-derived leucine aminopeptidase (ALAP) gene and possible association with hypertension. Hum Mutat 19: 251-257, 2002.

31. Bensadoun A and Berryman DE: Genetics and molecular biology of hepatic lipase. Curr Opin Lipidol 7: 77-81, 1996.

32. Tahvanainen E, Syvanne M, Frick MH, et al: Association of variation in hepatic lipase activity with promoter variation in the hepatic lipase gene. The LOCAT Study Investigators. J Clin Invest 101: 956-960, 1998.

33. Shohet RV, Vega GL, Anwar A, Cigarroa JE, Grundy SM and Cohen JC: Hepatic lipase (LIPC) promoter polymorphism in men with coronary artery disease. Allele frequency and effects on hepatic lipase activity and plasma HDL-C concentrations. Arterioscler Thromb Vasc Biol 19: 1975-1978, 1999.

34. Guerra R, Wang J, Grundy SM and Cohen JC: A hepatic lipase (LIPC) allele associated with high plasma concentrations of high density lipoprotein cholesterol. Proc Natl Acad Sci USA 94: 4532-4537, 1997

35. Couture P, Otvos JD, Cupples LA, et al: Association of the C$514 \mathrm{~T}$ polymorphism in the hepatic lipase gene with variations in lipoprotein subclass profiles: The Framingham Offspring Study. Arterioscler Thromb Vasc Biol 20: 815-822, 2000.

36. Isaacs A, Sayed-Tabatabaei FA, Njajou OT, Witteman JCM and van Duijn CM: The $-514 \mathrm{C}$-T hepatic lipase promoter region polymorphism and plasma lipids: a meta-analysis. J Clin Endocrinol Metab 89: 3858-3863, 2004.

37. Tanaka Y, Morimoto I, Nakano Y, et al: Osteoblasts are regulated by the cellular adhesion through ICAM-1 and VCAM-1. J Bone Miner Res 10: 1462-1469, 1995.

38. Tanaka Y, Maruo A, Fujii K, et al: Intercellular adhesion molecule 1 discriminates functionally different populations of human osteoblasts: characteristic involvement of cell cycle regulators. J Bone Miner Res 15: 1912-1923, 2000.

39. Harada H, Kukita T, Kukita A, Iwamoto Y and Iijima T: Involvement of lymphocyte function-associated antigen-1 and intercellular adhesion molecule-1 in osteoclastogenesis: a possible role in direct interaction between osteoclast precursors. Endocrinology 139: 3967-3975, 1998.

40. Lavigne P, Benderdour M, Lajeunesse D, Shi Q and Fernandes JC: Expression of ICAM-1 by osteoblasts in healthy individuals and in patients suffering from osteoarthritis and osteoporosis. Bone 35: 463-470, 2004.

41. Borozdenkova S, Smith J, Marshall S, Yacoub M and Rose M Identification of ICAM-1 polymorphism that is associated with protection from transplant associated vasculopathy after cardiac transplantation. Hum Immunol 62: 247-255, 2001.

42. Podgoreanu MV, White WD, Morris RW, et al: Inflammatory gene polymorphisms and risk of postoperative myocardial infarction after cardiac surgery. Circulation 114: I-275-I-281, 2006. 